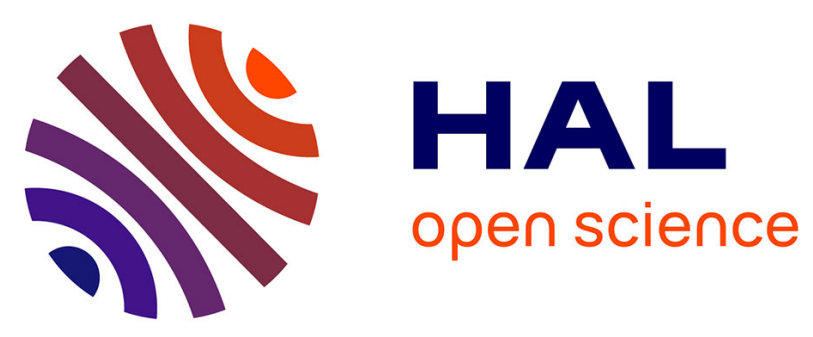

\title{
Multi-zone marine protected areas: assessment of ecosystem and fisheries benefits using multiple ecosystem models
}

\author{
X. Corrales, D. Vilas, C. Piroddi, J. Steenbeek, Joachim Claudet, J. Lloret, A. \\ Calò, A. Di Franco, T. Font, A. Ligas, et al.
}

\section{To cite this version:}

X. Corrales, D. Vilas, C. Piroddi, J. Steenbeek, Joachim Claudet, et al.. Multi-zone marine protected areas: assessment of ecosystem and fisheries benefits using multiple ecosystem models. Ocean and Coastal Management, 2020, 193, pp.105232. 10.1016/j.ocecoaman.2020.105232 . hal-03034139

\section{HAL Id: hal-03034139 \\ https://hal.science/hal-03034139}

Submitted on 1 Dec 2020

HAL is a multi-disciplinary open access archive for the deposit and dissemination of scientific research documents, whether they are published or not. The documents may come from teaching and research institutions in France or abroad, or from public or private research centers.
L'archive ouverte pluridisciplinaire HAL, est destinée au dépôt et à la diffusion de documents scientifiques de niveau recherche, publiés ou non, émanant des établissements d'enseignement et de recherche français ou étrangers, des laboratoires publics ou privés. 
1 To be re-submitted to Ocean and Coastal Management

2 Multi-zone marine protected areas: assessment of ecosystem and fisheries

3 benefits using multiple ecosystem models

4 Corrales, X. ${ }^{1,2,3}$; Vilas, D. ${ }^{1,2,4,5}$; Piroddi, C. ${ }^{6}$; Steenbeek, J. ${ }^{2}$; Claudet, J. ${ }^{7}$; Lloret, J. ${ }^{8}$; Calò, 5 A. ${ }^{9,10}$; Di Franco, A. ${ }^{9,11}$; Font, T. ${ }^{8}$; Ligas, A. ${ }^{12}$; Prato, G. ${ }^{13}$; Sahyoun, R. ${ }^{13}$; Sartor, P. ${ }^{12}$; 6 Guidetti, P. ${ }^{9,14}$; Coll, M. ${ }^{1,2}$.

7 1. Institut de Ciències del Mar (ICM-CSIC), P. Marítim de la Barceloneta, 37-49, 08003

8 Barcelona, Spain.

9 2. Ecopath International Initiative (EII), Barcelona, Spain.

10 3. AZTI, Txatxarramendi ugartea z.g. 48395. Sukarrieta, Spain.

11 4. Nature Coast Biological Station, Institute of Food and Agricultural Sciences, 12 University of Florida, Cedar Key, FL 32625, United States.

13 5. Fisheries and Aquatic Sciences Program, School of Forest Resources and 14 Conservation, University of Florida, Gainesville, FL 32611, United States.

6. European Commission, Joint Research Centre, Via Fermi 2749, 21027 Ispra, Italy.

7. National Center for Scientific Research, PSL Université Paris, CRIOBE, USR 3278 CNRS-EPHE-UPVD, Maison des Océans, 195 rue Saint-Jacques 75005 Paris, France.

8. University of Girona, Faculty of Sciences. C/ Maria Aurèlia Capmany 69. 17003. Girona, Spain

9. Université Côte d'Azur, CNRS, UMR 7035 ECOSEAS, Parc Valrose 28, Avenue Valrose, 016108, Nice, France.

10. Dipartimento di Scienze della Terra e del Mare, Università di Palermo. 90123. Palermo, Italy,.

11. Stazione Zoologica Anton Dohrn, Dipartimento Ecologia Marina Integrata, Sede Interdipartimentale della Sicilia, Lungomare Cristoforo Colombo (complesso Roosevelt), 90149 Palermo, Italy.

12. Consorzio per il Centro Interuniversitario di Biologia Marina ed Ecologia Applicata, V.le Sauro 4, 57128, Livorno, Italy.

13. WWF Italy, Italy. 
30 14. CoNISMa, P.le FLaminio 9, 00196 Roma, Italy.

31 Contact author: xavi.corrales.ribas@gmail.com

32 
34 The current alarming state of many coastal ecosystems and fisheries calls for the 35 development of tools to support recovery of exploited stocks, ensure their sustainable 36 exploitation and protect marine ecosystems. Multi-zone Marine Protected Areas (MPAs)

37 are often advocated to reconcile conservation and fisheries benefits. However, while there 38 is a consensus about the ecological benefits whether such types of MPAs can really provide 39 both benefits is still uncertain. Here, we analysed three existing Northwestern 40 Mediterranean multi-zone MPAs (Cerbère-Banyuls, Cap de Creus and Medes Islands) 41 using a comparative temporal ecosystem modelling approach to assess their effectiveness 42 over time in recovering marine resources and ecosystem in the area. Our results showed 43 differences in the ecological effectiveness of the three MPAs, potentially driven by MPA 44 design, management and implementation features. Temporal increases of benefits were 45 small, whenever detected, and showed slight recoveries of some target species and 46 ecological indicators, mostly in Cerbère-Banyuls and Medes Islands MPAs. Our results 47 confirm the benefits of protection to coastal marine resources and ecosystems when MPAs 48 are enforced but highlight the current limitations of the three MPAs due to their small size 49 and the significant impacts of small-scale and recreational fisheries. This study illustrates 50 the capability to evaluate protection effects of small multi-zone MPAs with an ecosystem 51 modelling perspective and represents the baseline to develop future scenarios of alternative 52 management options to foster ecosystem recovery and resource rebuilding in the studied 53 MPAs.

54 Keywords: Northwestern Mediterranean Sea; Ecopath model; Marine Protected Areas, 55 Small-scale fisheries; Recreational fisheries, Ecological indicators. 


\section{Introduction}

58 Coastal and marine ecosystems provide multiple ecosystem goods and services (Costanza,

59 d'Arge et al. 1997; Martínez, Intralawan et al. 2007). However, the provision of these

60

61

62

63

64

65

66

67

68

69

70

71

72

73

74

75

76

77

78

79

80

81

82

83

84

85

86 ecosystem goods and services can be degraded as human demand for resources and the associated activities increase in number, frequency, magnitude and spatial coverage (MEA 2005; Worm, Barbier et al. 2006; Pauly and Zeller 2016). Currently, marine ecosystems are under increasing threat from a range of stressors including overfishing, climate change, biological invasions, pollution, aquaculture and habitat degradation, directly or indirectly caused by multiple human activities (Costello, Coll et al. 2010; Halpern, Frazier et al. 2015). The relationships and interactive effects of multiple stressors are highly complex, and largely unknown or even highly uncertain (Crain, Halpern et al. 2009; Côté, Darling et a1. 2016).

In recognition of the complex interrelationship between marine organisms, multiple human activities, and ecosystem functioning and services, more comprehensive frameworks to manage marine ecosystems are required, such as the ecosystem-based management (EBM) (Leslie and McLeod 2007; Long, Charles et al. 2015). The overall objective of this approach is to maintain ecosystems as a whole "in healthy, productive and resilient conditions allowing them to provide the needed ecosystem services to society" (McLeod, Lubchenco et al. 2005). Within this context, Marine Protected Areas (MPAs hereafter) are considered to be a key management tool for EBM as they are expected to mitigate human impacts, recover exploited resources and support their sustainable use, conserve or restore habitats and biodiversity, maintain and enhance ecosystem services and reduce conflicts between users (Lester, Halpern et al. 2009; Halpern, Lester et al. 2010; Leenhardt, Low et al. 2015). A MPA is a discrete area of the sea established to achieve the long-term conservation of natural resources therein (Claudet 2011). The level of protection within MPAs can vary from areas of full protection (FPAs, also called marine reserves or no-take areas), where all extractive activities (e.g., fishing) are prohibited while some nonextractive activities (e.g. diving) can be allowed; to areas of partial protection (PPAs), where some human activities (e.g. small-scale and recreational fisheries) are allowed but strictly regulated (Horta e Costa, Claudet et al. 2016). Conservation benefits of MPAs 
87 largely vary due to their intrinsic features, including their design, the level of enforcement, 88 their conservation goals and organization (Guidetti, Milazzo et al. 2008; Di Franco, Thiriet et al. 2016; Giakoumi, McGowan et al. 2018; Scianna, Niccolini et al. 2019). In addition, networks of MPAs could provide greater benefits than the sum of individual MPAs benefits

91 (Gaines, White et al. 2010; Grorud-Colvert, Claudet et al. 2014). A network of MPAs is a system of individual MPAs that operates synergistically to achieve ecological objectives more effectively than individual MPAs could fulfil alone (IUCN-WCPA 2008).

Within the EBM, ecological modelling has been proven to be a suitable tool to merge available ecological information into a coherent form to obtain insights about how 96 ecosystems are structured and impacted by human activities and environment, and delivering ecosystem services (Link 2010; Christensen and Maclean 2011). Although quantitative models have become a key tool to assess the extent to which MPAs are able to achieve their conservation targets (Fulton, Bax et al. 2015), the understanding of MPA effects on ecological processes and ecosystem function is still scarce (Cheng, Altieri et al. 2019). For instance, it is mostly unknown if protection benefits inside fully protected areas extend to partially areas and beyond, and if those benefits have the potential to cascade through the ecosystem components. There is little evidence that multi-zone MPAs (i.e., those including both FPAs and PPAs) provide fisheries benefits inside partially protected areas and it is unknown what are the drivers of multi-zone MPAs.

Although considered a hotspot of biodiversity (Coll, Piroddi et al. 2010), the Mediterranean Sea has been largely altered by anthropogenic stressors for a long time (Coll, Piroddi et al. 2012; Micheli, Halpern et al. 2013; Halpern, Frazier et al. 2015), that have determined dramatic changes on its ecosystems especially during the last 50 years (Azzurro, Moschella et al. 2011; Maynou, Sbrana et al. 2011; Piroddi, Coll et al. 2017). In order to address this 112 internationally established protected areas) have been implemented in the Mediterranean 113 Sea in the last decades. Within this context, several studies have modelled MPAs in the 114 Mediterranean Sea with the aim to evaluate their effects on the ecosystem and the impacts 115 of small-scale and recreational fisheries on marine resources (Albouy, Mouillot et al. 2010;

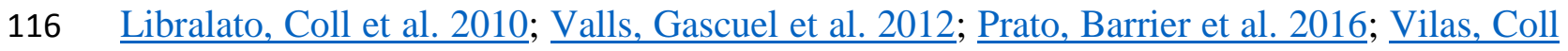


117 et al. Submitted). However, none of the existing studies modelled simultaneously the multi118 zone nature of Mediterranean MPAs nor a series of neighbouring MPAs, potentially 119 constituting a network of protected areas. In addition, the study of the historical effects of 120 MPAs has not been pursued due to difficulties to gather historical data about protection 121 effects. In this study we modelled three relatively well studied MPAs from the 122 Northwestern Mediterranean Sea with a historical perspective: Cerbère-Banyuls, Cap de 123 Creus and Medes Islands. Our aims were to: (1) quantify the main structural and functional 124 traits of the three multi-zone MPAs, and (2) assess how exploitation and protection regimes 125 affected these marine ecosystems over time, using a comparative approach to identify 126 commonalities and differences between MPAs. 


\section{Materials \& Methods}

129

130

131

132

133

134

135

136

137

138

139

140

141

142

143

144

145

146

147

148

149

150

151

152

153

154

155

156

\subsection{Study area}

We studied three MPAs in the Northwestern Mediterranean Sea: Cerbère-Banyuls (France), Cap de Creus (Spain) and Medes Islands (Spain) (Fig. 1). These MPAs include one Fully Protected Area (FPA) and one (Cerbère-Banyuls and Medes Islands) or more (Cap de Creus) Partially Protected Areas (PPAs) (Fig. 1). While in the FPAs all extractive activities are forbidden, in PPAs both small-scale and recreational fisheries are allowed except in Medes Islands MPA, where recreational fisheries are prohibited.

The three MPAs comprise a similar depth range between ca. 0 and 60 meters, and several vulnerable species such as the Mediterranean seagrass (Posidonia oceanica), dusky grouper (Epinephelus marginatus) and red coral (Corallium rubrum), can be found in these MPAs. In addition to the protected zone scheme (FPA and PPA), we included in our study the immediate unprotected areas (UPAs) surrounding each MPA (Fig. 1 and Table 1), in order to add the adjacent non-protected waters where some species found inside the MPAs can theoretically forage and move to (Di Lorenzo, Claudet et al. 2016). The boundaries of the unprotected areas were selected taking into account that they had similar ecological and oceanographic features (i.e., same depth range and habitats) to the MPA, and they constituted part of the Parc (Cap de Creus and Medes Islands) and/or were adjacent to the MPA (Cerbère-Banyuls) (Fig. 1).

\subsection{Modelling approach - Ecopath and Ecosim}

The three MPA models were developed using Ecopath with Ecosim approach (EwE 6.6 version) (Christensen and Walters 2004; Christensen, Walters et al. 2008). We used the static Ecopath model to provide a "snapshot" of the ecosystem in terms of flows and biomasses for a defined period of time. To develop the food-web model we used functional groups, which consist of ontogenetic fractions of a species, single species or groups of species sharing common ecological traits. The baseline models of each MPA were developed taking into account the contribution of each zone to the whole MPA based on a previous study (Vilas, Coll et al. Submitted). Afterwards, we used the time-dynamic model Ecosim, which describes the temporal dynamics of species biomass and flows over time by 
accounting for changes in predation, consumption rate, fishing and the environment (Walters, Christensen et al. 1997; Christensen and Walters 2004). A short description of the modelling approach is given in the Supplementary Online Material (SOM hereafter) 1; and a detailed information of the EwE approach is documented in Christensen and Walters (2004) and Heymans, Coll et al. (2016).

\subsection{Functional groups and input data}

\subsubsection{Functional groups}

A meta-web structure defined for the Western Mediterranean Sea model (Coll, Steenbeek et al. 2019) developed under the Safenet Project (Sustainable fisheries in EU Mediterranean waters through a network of MPAs) was used and adapted to our study area. Specifically, we removed those functional groups (hereafter FGs) that did not occur in the study area (i.e., FGs that include species that inhabit deeper waters or that live offshore). The final food-web structure contained 64 FGs for Cerbère-Banyuls MPA and 67 FGs for Cap de Creus MPA and Medes Islands MPA (SOM 2).

\subsubsection{Ecopath input data and balancing procedure}

The Ecopath models represented a situation of the Cerbère-Banyuls MPA for 2013, while the Cap de Creus MPA and the Medes Islands MPA represented an average situation for the period 2005-2008 and 2000-2004, respectively. These periods of time to model the MPAs were selected considering the best available biomass data (SOM 2 for details on the parameterization of each functional group). Input parameters were obtained using similar procedures as those documented in Coll, Palomera et al. (2006), Corrales, Coll et al. (2015),

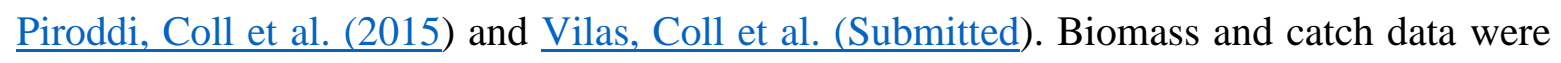
scaled using data from models of each management unit (FPA, PPA and UPA) developed

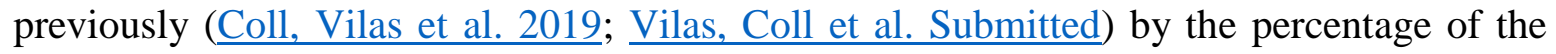
area of each management unit to the whole MPA (SOM 2 for details on parameterization of each functional group).

Production $\left(\mathrm{P} / \mathrm{B}\right.$, year $\left.{ }^{-1}\right)$ and consumption $\left(\mathrm{Q} / \mathrm{B}\right.$, year $\left.{ }^{-1}\right)$ rates were estimated through the application of empirical equations (Heymans et al., 2016), taken from literature or from 
other models developed in the Northwestern Mediterranean Sea (Coll, Palomera et al. 2006; Corrales, Coll et al. 2015; Coll, Vilas et al. 2019).

The trophic information to populate the diet matrix was compiled using published studies on stomach content analyses, giving preference to local or surrounding areas (SOM 2). We used the Diet Matrix Calculator (Steenbeek 2018), a custom-built extraction tool that automatizes the process of selecting and scaling diet data. Drawing on a large library of published diet studies, the Diet matrix calculator tool selects the most likely suitable diet studies for a specific model area, based on a range of criteria, and generates a diet composition matrix with accompanying pedigree index for each predatory functional group. Due to the small sizes of the investigated MPA and the capacity of some species to move greatly (Gell and Roberts 2003; Grüss, Kaplan et al. 2011), we set a fraction of the diet composition as import for all MPA based on the time that these species spent foraging outside the areas and biological and ecological traits such as size, behavior and ecology of species of each functional group (Table 1 in SOM 3).

To achieve mass-balance of the baseline models, we implemented a manual procedure following a top-down approach (starting from the groups with higher trophic levels) modifying appropriate input parameters (Table 2 in SOM 3) and following the best practice guidelines provided in the literature (Heymans, Coll et al. 2016). In addition, the PREBAL analysis was used to ensure that the input data complied with general ecologic principles and to guide modifications through the balancing procedure (Link 2010). Detailed explanations of these procedures are given in SOM 3 and the final diet matrixes are provided in SOM 4.

The pedigree routine (Christensen and Walters 2004) was used to evaluate the quality of the models and the uncertainty associated with the input parameters and to guide modifications in balancing the model. A detailed explanation of this routine is given in SOM 3.

\subsubsection{Ecosim historical time series fitting.}

The model representing Cerbère-Banyuls MPA ecosystem during the 2013-2017 period was fitted to time series of historical data, while for Cap de Creus MPA and the Medes Islands MPA, the Ecosim model was fitted to time series of 2008-2017 and 2004-2017 
214 periods, respectively (Table 1 in SOM 5). We used historical fishing effort trends to drive

215 the fisheries of the models, while biomass and catch time series were used to calibrate the 216 model and compare predicted to observed results (see SOM 5 for details), respectively,

217 following previous studies in the Mediterranean Sea and best practices of EwE (Coll,

218 Navarro et al. 2013; Heymans, Coll et al. 2016; Corrales, Coll et al. 2017).

219 The models were fitted by using the Stepwise Fitting Procedure (Scott, Serpetti et al. 2016).

220 This procedure tests alternative hypotheses related to the impact of fishing, changes in 221 predator-prey dynamics (vulnerabilities), changes in primary production (production

222 anomalies) or all of the above together (Table 2) (Mackinson, Daskalov et al. 2009;

223 Heymans, Coll et al. 2016). This procedure estimates different vulnerability parameters and

224 primary productions anomalies to improve model fits by comparing model predictions to 225 observed data using the sum of squares (SS) statistics and to find the statistically "best fit"

226 model based on Akaike's Information Criterion (AIC), which penalizes the

227 overparameterization of the model (Mackinson, Daskalov et al. 2009; Heymans, Coll et al.

228 2016). In this study, the maximum number of parameters that could be estimated were 19

229 (Cerbère-Banyuls), 51 (Cap de Creus) and 48 (Medes Islands), respectively.

230 Finally, we manually evaluated a range of models fits with the lowest AIC values to 231 identify the best final model, which led to a credible behavior (Heymans, Coll et al. 2016), 232 following previous studies (e.g., Corrales, Coll et al. 2017).

\section{$233 \quad 2.4$ Model analyses and ecological indicators}

\subsubsection{Ecological indicators of initial conditions}

235 To analyze the food-web structure of the three MPAs, we used the biomasses of selected 236 FGs, trophic flows and trophic levels (TLs) within the flow diagram. The TL was also used 237 to analyze the ecological position of the FG of the three MPA models (Lindeman 1942; $238 \quad$ Stergiou and Karpouzi 2001)

239 Several ecological indicators were also computed to describe the structure and functioning 240 of the ecosystems and were divided into four groups using the ECOIND plug-in (Coll and $241 \quad$ Steenbeek 2017): 
242 (1) Biomass-based: calculated from the biomass of components included in the food243 web model, they could provide valuable information to evaluate MPAs effectiveness 244 (Micheli, Halpern et al. 2004; Claudet, Osenberg et al. 2008). We included Total Biomass $245\left(\mathrm{~TB}, \mathrm{t} \cdot \mathrm{km}^{-2} \cdot\right.$ year $\left.^{-1}\right)$, Biomass of Fish species $\left(\mathrm{FB}, \mathrm{t} \cdot \mathrm{km}^{-2} \cdot \mathrm{year}^{-1}\right)$, and Kempton's Q diversity 246 index (QI).

247 (2) Trophic-based: reflect the TLs for different groups of the food web, provide 248 information on the structure of the ecosystem and are used to quantify the impact of fishing 249 (Rochet and Trenkel 2003). We selected TL of the community (TLc), TL of the 250 community, TL of the community including organisms with TL $\geq 3.25$ (TL3.25) and TL of 251 the community including organisms with TL $\geq 4$ (TL4).

252 (3) Species and size-based: based on species traits and conservation status, they could 253 offer insights of the effects of MPAs (Claudet, Osenberg et al. 2010). We selected biomass 254 of IUCN-endangered species biomass in the community $\left(\mathrm{t} \cdot \mathrm{km}^{-2} \cdot \mathrm{year}^{-1}\right)$, mean length of fish 255 in the community (ML, cm) and mean life span of fish community (MLS, year).

256 (4) Catch-based: based on catch, they reflect the fishing strategy of the fisheries and are 257 used to quantify the impact of fishing (Hilborn and Walters 1992; Pauly, Christensen et al. 258 1998). We included total catch ( $\mathrm{TC} t \mathrm{~km}^{-2} \cdot \mathrm{year}^{-1}$ ), trophic level of the catch (TLc), intrinsic 259 vulnerability index of catch (VI).

260 The Mixed Trophic Impact (MTI) analysis was performed to assess the direct and indirect 261 impact in the food web that a hypothetical increase in the biomass of one functional group 262 would have on the biomasses of all the other functional groups in the food web, including 263 the fishing fleets (Ulanowicz and Puccia 1990; Christensen, Walters et al. 2008). To 264 evaluate the impact of small-scale fisheries on the MPAs, the MTI was used to quantify the 265 direct and indirect impact of each fishery on the functional groups for the studied MPAs, 266 and their potential competition and trade-offs between them.

267 Finally, to identify the key species within the ecosystem (both keystone and structuring 268 species), we calculated the keystoneness index developed by Valls, Coll et al. (2015) of the 269 most important reef functional groups. A keystone group is defined as a predator species 
with a large and broad impact on the food web despite its low biomass (Paine 1966; Paine 1969; Valls, Coll et al. 2015).

\subsubsection{Time-dynamic analyses}

Once the fitting procedure was completed, we used the best fit model to examine biomass and catch time series predicted by the model to explore the dynamics of selected functional groups. We selected four target species due to their role in terms of biomasses and commercial interest: the common two-banded seabream (Diplodus vulgaris), white seabream (D. sargus sargus), common dentex (Dentex dentex) and groupers (this group was mainly represented by Epinephelus marginatus). These species play an important role in the ecosystem as high trophic level predators or intermediate trophic species and are of great importance in small-scale and recreational fisheries. In addition, the previous selection of ecological indicators from the ECOIND plug-in was used to describe ecological changes in the ecosystem over time (Coll and Steenbeek 2017).

The Monte Carlo (MC) uncertainty routine and the ECOSAMPLER plug-in were employed to assess the impact of uncertainty in Ecopath input parameters on Ecosim simulations (Heymans, Coll et al. 2016; Coll and Steenbeek 2017; Steenbeek, Corrales et al. 2018). We ran $500 \mathrm{MC}$ simulations based on the sensibility of Ecopath input parameters obtained from the pedigree routine (SOM 3). Results from the MC simulations were used to plot the confidence intervals of the selected ecological indicators in Ecopath and to plot the $5^{\text {th }}$ and $95^{\text {th }}$ percentile confidence intervals for the Ecosim outputs. Finally, we used the Spearman's rank correlation to evaluate the presence of significant trends (either increasing or decreasing) in model outputs (biomass, catch and ecological indicators), following previous studies (e.g., Corrales, Coll et al. 2017).

\section{Results}

\subsection{Structure and functional traits of protected areas}

The pedigree index values of the three MPA models showed similar values, ranging from 0.41 to 0.51 . The highest pedigree values were obtained for Cerbère-Banyuls (0.51), followed by Medes Islands (0.45) and Cap de Creus (0.41). 
The visualization of trophic links and flows between functional groups highlighted the complexity of these coastal ecosystems due to the large number of trophic links between functional groups and the important role of detritus (FG 65) and other macro-benthos (FG 51) in transferring energy up to the food web (Fig. 2).

The functional groups of the models ranged from trophic level (TL) of 1 for primary producers (FG. 60-67) and detritus groups (FG 66-67) to $\mathrm{TL}=4.2$ for both groups of dolphins (FG 1-2) (Fig. 2 and Table 3 in SOM 3). Invertebrates groups were classified with a TL between 2 and 3.5, with benthopelagic cephalopods (FG 41) showing higher TLs. Fish had TLs between 3 and 4, with the exception of salema (FG 33) and mugilidae (FG 34), which showed lower TL due to their herbivorous and detritivore behaviors. Overall, similar TLs were found for the three MPAs.

Total and fish biomass displayed similar patterns, with the highest biomass values found for Cerbère-Banyuls and Medes Islands and lower values in Cap de Creus (Fig. 3). Conversely, Kempton's Q Index presented a higher value in Cap de Creus, followed by Medes Islands and Banyuls-Cerbère (Fig. 3). With the exception of TL of the community 4, trophic based indicators also presented higher values for Cerbère-Banyuls, followed by Medes Islands and Cap de Creus (Fig. 3). Species and size-based indicators showed that Cerbère-Banyuls presented the highest values for ML of fish community and IUCN species B, followed by Cap de Creus and Medes Islands (Fig. 3), while MLS of fish community was higher in Cap de Creus, followed by Cerbère-Banyuls and Medes Islands (Fig. 3). Total catch showed similar values between Cap de Creus and Medes Islands, while Cerbère-Banyuls had the lowest value (Fig. 3). TL of the catch and the Intrinsic Vulnerability Index presented similar values in Cerbère-Banyuls and Cap de Creus, while Medes Islands had the lowest value (Fig. 3).

The keystoneness index identified groupers (FG 27), common dentex (FG 24), other commercial medium demersal fishes (FG 31) and non-commercial medium demersal fishes (FG 32) as keystones species in the three MPAs, followed by red scorpionfish (Scorpaena scrofa) (FG 25) and Scorpaenidae (FG 26) (Fig. 4). 
The MTI analysis highlighted that the small-scale fisheries had the most widespread negative impact on many FG of all MPAs, especially in Cerbère-Banyuls, while the impact of recreational fisheries was more prominent in Cap de Creus and Medes Islands (Fig. 5). This analysis showed strong negative impact of fisheries on target species such as other large pelagic species (FG 8), common dentex (FG 24), and groupers (FG 27) while competitors or preys of those species may be positively impacted such as white seabream (FG 22), common two-banded seabream (FG 23) and brown meagre (Sciaena umbra) (FG 28) (Fig. 5). Results also highlighted that each fishery had a negative impact on itself due to self-competition for resources according to the MTI results and that competition between fisheries was complex (Fig 5). While small-scale fisheries had positive impacts on recreational fisheries in Cerbère-Banyuls MPA, recreational fisheries had slightly negative impacts on small-scale fisheries (Fig. 5a). On the contrary, small-scale fisheries had negative impacts on recreational fisheries in Cap de Creus and Medes Islands MPAs, while recreational fisheries had positive impacts on the small-scale fisheries (Fig. $5 \mathrm{~b}$ and c).

\subsection{Ecological impacts of protection over time}

The best-fitted food wed temporal models were obtained when trophic interactions, fishing, and primary production anomaly were included in the model configuration for all MPAs (Step 8 in Table 3). However, for all MPAs the best model was not able to reproduce the trends of white seabream, common two-banded seabream, common dentex and groupers satisfactorily, which we selected as target groups of this study. Therefore, we moved through the fitting procedure analysis to find the model that was able to reproduce the trends of most of the groups (and specifically the target groups) and was highly significant. We finally choose a model fit with 12 vulnerabilities and 3 spline points, 15 vulnerabilities and 3 spline points, and 11 vulnerabilities and 5 spline points for Cerbère-Banyuls, Cap de Creus and Medes Islands models respectively, as the best options (Step 8 in Table 3).

Observed biomass and catch time series were satisfactorily reproduced by model predictions for most of the target groups (Fig. 6 and SOM 6, 7 and 8) when using the chosen fitted model. The temporal models showed a non-significant biomass pattern of white seabream in Cerbère-Banyuls, firstly decreasing and later increasing, and in Cap de

Creus, where firstly increased and later decreased, while in Medes Islands it presented a 
significant decreasing biomass trend (Fig 6). The models showed similar biomass patterns for common two-banded seabream, highlighting a non-significant trend in Cerbère-Banyuls and Cap de Creus and a significant decreasing trend in Medes Islands (Fig. 6). We observed a significant decreasing biomass trend of common dentex in Cerbère-Banyuls, while in Cap de Creus and Medes this group showed non-significant biomass trends (Fig. 6). The results highlighted a non-significant biomass pattern of groupers in Cerbère-Banyuls, while they significantly increased in Cap de Creus and Medes Islands (Fig 6). However, in Medes Islands the model did not capture well the overall declining trend of observations for groupers biomass.

Regarding the temporal changes of ecological indicators, the Kempton's Index showed a non-significant trend in Cerbère-Banyuls and Cap de Creus, while in Medes Islands, the Kempton's Index significantly increased during the simulated period (Fig. 7). The TL of the community presented a non-significant pattern in Cerbère-Banyuls and Cap de Creus, while in Medes Islands significantly decreased (Fig. 7). IUCN species biomass significantly declined in Cerbère-Banyuls, while in Cap de Creus and Medes Islands presented nonsignificant patterns (Fig. 7). Total catches highlighted non-significant trends in CerbèreBanyuls and Cap de Creus (in the last one firstly increasing and then decreasing), while in Medes Islands, total catches significantly decreased (Fig. 7).

\section{Discussion}

\subsection{Structure and functional traits of protected areas}

Overall, ecological indicators showed similar patterns, with the highest values in BanyulsCerbère MPA, followed by Medes Islands and Cap de Creus MPAs. This may be related to differences in the ecological effectiveness of the three MPAs, which is partly explained by MPA design, management and implementation features (e.g. extent of area protected, fully protected area enforcement, time since protection, MPA design) (Claudet, Osenberg et al. 2008; Guidetti, Milazzo et al. 2008; Edgar, Stuart-Smith et al. 2014; Giakoumi, Scianna et al. 2017; Di Franco, Plass-Johnson et al. 2018). The lack of enforcement is one of the most relevant issues concerning MPAs in the Mediterranean context (Fenberg, Caselle et al. 2012). Within this context, while Cerbère-Banyuls and Medes MPAs are considered to 
have a high level of enforcement (Sala, Ballesteros et al. 2012; Giakoumi, Scianna et al. 2017), Cap de Creus has been considered a MPA only on paper due to a lack of sufficient enforcement (Lloret, Zaragoza et al. 2008; Lloret, Zaragoza et al. 2008). In fact, total catches were higher in Cap the Creus than in the other two MPA; with Cerbère-Banyuls presenting the lowest total catches. Total catches are expected to be higher in well designed and enforced MPAs (Halpern, Lester et al. 2009; Di Lorenzo, Claudet et al. 2016), so our results could be explained by the allowed and/or real fishing effort and the small effects of these MPAs in PPAs and adjacent areas. Horta e Costa, Claudet et al. (2016) presented a novel classification system for MPAs by scoring allowed uses in each management unit based on their impacts on biodiversity. In this scale, Cerbère-Banyuls obtained a rate of 4.7, being a highly protected area and Medes 6.4 being less well protected (Horta e Costa, Claudet et al. 2016). Although Cap de Creus was not included in this study, we could expect a higher MPA index because of its smaller FPA and allowed uses. These features (smallest FPA and weak enforcement) and the fact that Cap de Creus is the newest (Table 1) MPA in the study, could suggest that the year of establishment, enforcement and the size of protected areas have a strong effect on MPA effects, in line with other studies (Claudet, Osenberg et al. 2008; Guidetti, Milazzo et al. 2008).

Our results also indicated that both the small-scale and recreational fisheries can have a notable impact affecting organisms from lower to higher trophic levels. According to our study, small-scale fisheries had the largest negative ecological impacts. In fact, this fishery tends to develop its main activity inside the MPA or in surrounding areas (Goñi, Adlerstein et al. 2008; Stelzenmüller, Maynou et al. 2008). Recreational fisheries seemed to have larger impacts in the Spanish MPAs (Cap de Creus and Medes Islands MPA), while they had a negligible impact in Cerbère-Banyuls MPA, although the impact of recreational fisheries could be similar than the small-scale fisheries, as highlighted in coastal waters of Cap de Creus by Lloret, Zaragoza et al. (2008). This could be related to cultural reasons, differences in enforcement of each MPA and/or the reliability of catch data between study sites. In addition, our results highlighted that despite the recreational fisheries seemed to have an overall lower negative impact, it had strong negative impacts on vulnerable species such as common dentex and groupers (this group was mainly represented by Epinephelus marginatus) in Cap de Creus and Medes Islands MPAs, in line of the observed impact of 
small-scale and recreational fisheries on vulnerable species (Lloret, Biton-Porsmoguer et al. 2019), which is an important fact to consider when establishing management plans for these species. Our results also highlighted the competition for resources between both (smallscale and recreational) fisheries. Competition between both fisheries has become an important issue in coastal areas (especially in surrounding areas of MPAs), as they target similar species and fishing grounds (Chuenpagdee and Jentoft 2018; Lloret, Cowx et al. 2018). In small and touristic areas such as the ones in the present study, a strong competition between small-scale and recreational fishers could be expected due to the current economic, societal and environmental challenges of the small scale fisheries and the increasing importance of recreational fisheries as a leisure activity in these areas (Gómez and Lloret 2017).

\subsection{Ecological impacts of protection over time}

The temporal dynamic model of Cerbère-Banyuls predicted an increasing biomass pattern of white seabream and common two-banded seabream while common dentex and groupers largely decreased. The decrease of common dentex and groupers could be related to the impact of fishing, although fishing effort did not increase during the study period and initial fishing mortalities were not high. The increase of both seabream species could be explained by the reduction of their predators and/or by some other processes (e.g., increase in resources). In fact, common dentex and groupers are the most important predators of these species in terms of total consumption.

In contrast, the temporal dynamic model of Cap de Creus predicted a decreasing biomass pattern of white seabream, common two-banded seabream and common dentex while groupers increased. These results suggest a recovery of groupers population in Cap de Creus (Hereu Fina, Aspillaga Cuevas et al. 2017), despite the low level of enforcement, that could cause biomass reductions of their preys such as both seabream species. Similarly, the temporal dynamic model of Medes Islands highlighted decreasing trends for white seabream, common two-banded seabream and common dentex, while groupers slightly increased. These results evidence that under protection the food-web effects can play an important role and there are winners and losers as a result of the new ecological state, where results of protection can include cascading effects of predators on preys species 
(Edgar, Stuart-Smith et al. 2014; Cheng, Altieri et al. 2019) as well as an increase in competitive interactions (Micheli, Halpern et al. 2004).

Ecological indicators play an important role within the EBM framework as they are able to describe the condition of the ecosystem, its components and its functioning, to evaluate the impact of human activities in marine ecosystems and to inform management decisions (Shin and Shannon 2010; Tam, Link et al. 2017). In our study, ecological indicators showed overall contrasting results, as some indicators indicated recovery (e.g. Kempton's $\mathrm{Q}$ in the three MPAs) while others showed degradation patterns (e.g., TL of the community in the three MPAs). These contrasting results could respond to the limitation in historical data to represent ecosystem dynamics in the study area and could indicate limited recovery of species and ecosystems in the three MPAs.

The most notable effects of MPAs are an increase in abundance, average size and biomass inside protected areas (Lester, Halpern et al. 2009; Giakoumi, Scianna et al. 2017). Due to the increased density inside the MPA, adults and juveniles may move to adjacent areas (spillover effect) and therefore, higher fisheries yields in adjacent areas are expected (Goñi, Adlerstein et al. 2008; Di Lorenzo, Claudet et al. 2016). Larger abundance and sizes could entail higher reproductive potential of species, and eggs and larvae from recovered populations could then be exported to external unprotected locations, including adjacent ones (Gell and Roberts 2003; Harrison, Williamson et al. 2012). In addition, MPAs could restore ecosystem functioning (Cheng, Altieri et al. 2019). Although some of our temporal results showed potential recoveries (some target species, increases of predators and declines of prey, and some ecological indicators), our study evidences that they are still far from what we would expect from the temporal protection effects of MPAs, highlighting an overall modest historical positive effect of protection on these MPAs. These results are in line with Hereu Fina, Aspillaga Cuevas et al. (2017), which have pointed out illegal fishing as one of the main reasons for a lack of recovery and have called for further enhance the enforcement in Mediterranean MPAs.

\subsection{Data gaps, limitations and uncertainties}


474 Overall the input data used was of acceptable quality compared to the distribution of 475 pedigree values in other existing models (Morissette 2007; Lassalle, Bourdaud et al. 2014), 476 although they are among the lowest values in the Mediterranean Sea (Corrales, Coll et al. 477 2015). This could be due to the challenges of modelling small and local coastal areas, 478 where specific data is a strong requirement. In fact, limitations of available data are a 479 common concern for most Mediterranean MPAs (Prato, Barrier et al. 2016; Vilas, Coll et al. Submitted) despite there are monitoring programs inside these MPAs.

481 In general, there is a lack of biomass estimates for many functional groups, especially 482 regarding benthic invertebrates. One of the main hurdles to evaluate the impact of fishing 483 activities is to obtain realistic estimates of total catch (official and Illegal, Unregulated and 484 Unreported) (Pauly, Ulman et al. 2014; Pauly and Zeller 2016). In our study this challenge 485 is even higher due to the importance of recreational fishers and illegal fishing in coastal 486 areas, specifically in MPA and surrounding areas (e.g., Lloret, Zaragoza et al. 2008; Ben Lamine, Di Franco et al. 2018).

488

489

490

491

492

493 494 495 496

497 498 499 500 501 502 503

The capacity of ecosystem models to replicate trends increases with data availability and quality (Giron-Nava, James et al. 2017). Within this context, in Cerbère-Banyuls a maximum of four data points of biomass per functional group were available for the fitting procedure. The Medes Islands MPA model had the longest available time series, and thus presented a better and more informative fit, while the Cap de Creus MPA model showed an intermediate situation. This limited the capability to calibrate and validate the models and to track ecosystem dynamic status. Therefore, our results highlight the need to further monitor MPAs within the Mediterranean Sea and should inform future scientific research objectives in the area.

Despite these limitations, the models presented in this study were constructed using the best available data, including several sources of information including unpublished and ad hoc field data, expert knowledge and published data, and following the best practices in ecosystem modelling development (Heymans, Coll et al. 2016). The present models represent the first attempt to develop temporal MPA models that are nearly located and confirm the capability of EwE to evaluate protection effects within an ecological perspective in small MPAs even in cases of data limitations. 


\subsection{Concluding remarks}

Human activities have been concentrated in coastal ecosystems, resulting in a major modification of these marine areas (Halpern, Frazier et al. 2015). Since coastal areas account for a large amount of the global ecosystem services (Costanza, d'Arge et al. 1997), there is a need for the recovery of coastal marine ecosystems in order to ensure their ecological role. In addition, in recent decades, marine ecosystems have been increasingly impacted by other stressors, directly or indirectly induced by multiple anthropogenic activities (Halpern, Frazier et al. 2015). For example, sea warming and the spread of nonindigenous species represent a major challenge for conservation in Mediterranean ecosystems, especially in the Eastern Mediterranean Sea (Lejeusne, Chevaldonné et al. 2010; Katsanevakis, Coll et al. 2014). Organisms and ecosystems that have been already impacted by fishing are more vulnerable to these additional stressors (Occhipinti-Ambrogi and Savini 2003; Poloczanska, Burrows et al. 2016). MPAs, when properly managed, have demonstrated to be an effective tool to protect target species and habitats to local stressors such as fishing (Sala, Giakoumi et al. 2017), while their role in promoting resilience to regional and global stressors such biological invasions and climate change is debated (Giakoumi and Pey 2017; Roberts, O’Leary et al. 2017; Giakoumi, Pey et al. 2019). In highly impacted and crowded areas like the Northwestern Mediterranean Sea, the establishment of well-designed networks of well-enforced MPA is necessary to achieve "clean, healthy and productive" oceans (Good Environmental Status) according to the Marine Strategy Framework Directive (Fenberg, Caselle et al. 2012). Therefore, there is a need to better understand how current management options can contribute to the recovery and conservation of marine ecosystems and resources.

Within the EBM, ecosystem models and ecological forecasts have become an essential analytical and decision-making tool despite their limitations due to high uncertainties and complex ecosystem characteristics (Link, Ihde et al. 2012; Collie, Botsford et al. 2014; Maris, Huneman et al. 2017). They have the potential to provide insights of possible future impacts on marine ecosystems and can offer guidance to decision-makers by evaluating the trade-off between different management units and identify those measures that have the potential to meet conservation objectives (Fulton, Boschetti et al. 2015; Acosta, Wintle et 
534 al. 2016). However, in order to better assess MPA effectiveness and design, there is a need

535 to take into account economic and social attributes of the municipalities of the MPAs 536 (Bennett and Dearden 2014; Clarke, Thurstan et al. 2016). Therefore, the integration of the

537 social and economic components into ecosystem models needs to be promoted. Also future 538 research should try to assess how the benefits potentially delivered by MPAs in terms of 539 species recovery and increase of fisheries catches actually affect human well-being of local 540 communities inhabiting within and around MPAs.

541 This study is the baseline to develop future scenarios of alternative management options in 542 order to maximize the impacts of MPAs to their surrounding areas and fisheries 543 sustainability by alternative MPAs configurations. In addition, due to the vicinity of the 544 three MPAs along a latitudinal gradient, this study is a part of a nested modelling approach 545 with different geographic scales with the aim to assess the current effects of the actual 546 MPA network and to perform simulations of alternative MPA network configuration (Coll, 547 Steenbeek et al. 2019).

548 Acknowledgements

549 This work was funded by EU Research Project SAFENET ("Sustainable Fisheries in EU 550 Mediterranean waters through Network of MPAs). Call for proposal MARE/2014/41, Grant 551 Agreement n. 721708.

\section{Author Contributions}

$553 \mathrm{XC}, \mathrm{DV}, \mathrm{CP}, \mathrm{JS}$ and MC designed the study and analyses. CP, JS, JC, JL, AC, ADF, TF, 554 AL, GP, RS, PS, PG and MC contributed with material and analysis tools. XC, DV and MC 555 developed the models. XC, DV, CP, JS, JC, JL, AC, ADF; AL, GP, PG and MC interpreted 556 the results. XC wrote the manuscript with assistance from DV, JC and MC and input from 557 CP, JS, JL, AC, ADF, TF, AL, GP, RS, PS and PG.

\section{$558 \quad$ Tables legends}

559 Table 1. Surface area $\left(\mathrm{km}^{2}\right)$ covered by management units (MU) and year of creation of 560 each Marine Protected Area (MPA) of Cerbère-Banyuls, Cap de Creus and Medes Islands. 
561

562

563

564

565

566

567

568

569

570

571

572

573

574

575

576

577

578

579

580

581

582

583

584

585

586

587

588

$\mathrm{FPA}=$ Fully protected Area, $\mathrm{PPA}=$ partially protected area, UPA = unprotected area flanking the MPA.

Table 2. Overall fitting procedure applied to the three MPA models following the methodology suggested by Mackinson, Daskalov et al. (2009) and Heymans, Coll et al. $\underline{(2016)}$.

Table 3. Results of the fitting procedure of the three MPA of Cerbère-Banyuls, Cap de Creus and Medes Islands. The table shows the statistically "best" model for each step. Vs $=$ number of vulnerabilities estimated, PPsp = number of primary production spline points, $\mathrm{k}$ $=$ number of parameters $(\mathrm{Vs}+\mathrm{PPsp}), \% \mathrm{IF}=$ improved fit compared to the baseline AICc . The "best" models are highlighted in bold.

\section{Figure legends}

Figure. 1. The study area encompassing the three multi-zone MPAs in the Northwestern Mediterranean Sea with the fully protected areas (FPAs), partially protected areas (PPAs) and unprotected neighboring areas (UPAs).

Figure. 2. Flow diagram of Cerbère-Banyuls (a), Cap de Creus (b) and Medes Island (c) MPA models. The numbers identify the functional groups of the model (listed in SOM 2). The size of each circle is proportional to the biomass of the functional group. The thickness of the connecting lines is proportional to the magnitude of their trophic flows.

Figure. 3. Ecological indicators estimated for the three multi-zone MPA models of Cerbère-Banyuls, Cap de Creus and Medes Islands. Boxplot shows the distribution of values for an ecological indicator derived from the Monte Carlo routine while the dot represents the value of the indicator in the baseline Ecopath balanced model.

Figure. 4. Functional groups plotted against Keystone Index (Valls et al., 2015) and trophic level for Cerbère-Banyuls (a), Cap de Creus (b) and Medes (c) multi-zone MPA models. The numbers identify the functional groups of the model (listed in SOM 2). The size of the circles is proportional to the biomass of the functional group.

Figure. 5. Mixed Trophic Impact (MTI) analysis of the three MPA applied to the fisheries in a) Cerbère-Banyuls, b) Cap de Creus, and c) Medes Islands multi-zone MPA models. 
589 Figure. 6. Predicted (solid lines) versus observed (dots) biomass $\left(\mathrm{t} \cdot \mathrm{km}^{-2}\right)$ values for target 590 species of Cerbère-Banyuls, Cap de Creus and Medes Islands multi-zone MPAs models. 591 Blue shadows represent the 5\% and 95\% percentiles obtained using the Monte Carlo 592 routine. Rho and p-values result from Spearman's rank correlation test.

593 Figure. 7. Temporal trends of ecological indicators of Cerbère-Banyuls, Cap de Creus and 594 Medes Islands multi-zone MPAs models. Blue shadows represent the 5\% and 95\% 595 percentiles obtained using the Monte Carlo routine. Rho and p-values result from 596 Spearman's rank correlation test. 


\section{References}

Acosta, L. A., B. A. Wintle, et al. (2016). Using scenarios and models to inform decision making in policy design and implementation. Methodological assessment of scenarios and models of biodiversity and ecosystem services [S. Ferrier, K. N. Ninan, P. Leadley, R. Alkemade, L. A. Acosta, H.R. Akçakaya, L. Brotons, W.W.L. Cheung, V. Christensen, K. A. Harhash, J. Kabubo-Mariara, C. Lundquist, M. Obersteiner, H. Pereira, G. Peterson, R. Pichs-Madruga, N. Ravindranath, C. Rondinini and B.A. Wintle (eds.)]. IPBES. Bonn, Germany: 43-100.

Albouy, C., D. Mouillot, et al. (2010). "Simulation of the combined effects of artisanal and recreational fisheries on a Mediterranean MPA ecosystem using a trophic model." Marine Ecology Progress Series 412: 207-221.

Azzurro, E., P. Moschella, et al. (2011). "Tracking signals of change in Mediterranean fish diversity based on local ecological knowledge." PloS one 6(9): e24885.

Ben Lamine, E., A. Di Franco, et al. (2018). "Comparing commercial, recreational and illegal coastal fishery catches and their economic values: A survey from the southern Mediterranean Sea." Fisheries Management and Ecology 25(6): 456-463.

Bennett, N. J. and P. Dearden (2014). "Why local people do not support conservation: Community perceptions of marine protected area livelihood impacts, governance and management in Thailand." Marine Policy 44: 107-116.

Clarke, B., R. Thurstan, et al. (2016). "An investigation into the socio-cultural dimension of determining MPA effectiveness." Report prepared for Department of Environment, Water and Natural Resources, Adelaide.

Claudet, J. (2011). Marine protected areas: a multidisciplinary approach, Cambridge University Press.

Claudet, J., C. Osenberg, et al. (2010). "Marine reserves: fish life history and ecological traits matter." Ecological applications 20(3): 830-839.

Claudet, J., C. W. Osenberg, et al. (2008). "Marine reserves: size and age do matter." Ecology letters 11(5): 481-489.

Coll, M., J. Navarro, et al. (2013). "Ecological role, fishing impact, and management options for the recovery of a Mediterranean endemic skate by means of food web models." Biological Conservation 157: 108-120.

Coll, M., I. Palomera, et al. (2006). "Trophic flows, ecosystem structure and fishing impacts in the South Catalan Sea, Northwestern Mediterranean." Journal of Marine Systems 59(1): 63-96.

Coll, M., C. Piroddi, et al. (2012). "The Mediterranean Sea under siege: spatial overlap between marine biodiversity, cumulative threats and marine reserves." Global Ecology and Biogeography 21(4): 465-480.

Coll, M., C. Piroddi, et al. (2010). "The biodiversity of the Mediterranean Sea: estimates, patterns, and threats." PloS one 5(8): e11842.

Coll, M. and J. Steenbeek (2017). "Standardized ecological indicators to assess aquatic food webs: The ECOIND software plug-in for Ecopath with Ecosim models." Environmental Modelling \& Software 89: 120-130.

Coll, M., J. Steenbeek, et al. (2019). Report on the optimal configuration of the networks of management units in the study area to optimize fishing benefits and sustainability, and comparison with current networks. Sustainable Fisheries in EU Mediterranean waters through network of MPAs - Safenet MARE/2014/41 Deliverable 4.4:88.

Coll, M., J. Steenbeek, et al. (2019). Report describing the qualitative models. Sustainable Fisheries in EU Mediterranean waters through network of MPAs - Safenet MARE/2014/41 Deliverable 4.1:17. 
Coll, M., D. Vilas, et al. (2019). Report describing the quantitative models. Sustainable Fisheries in EU Mediterranean waters through network of MPAs - Safenet MARE/2014/41 Deliverable 4.2:62.

Collie, J. S., L. W. Botsford, et al. (2014). "Ecosystem models for fisheries management: finding the sweet spot." Fish and Fisheries.

Corrales, X., M. Coll, et al. (2017). "Hindcasting the dynamics of an Eastern Mediterranean marine ecosystem under the impacts of multiple stressors." Marine Ecology Progress Series 580 : 17-36.

Corrales, X., M. Coll, et al. (2015). "Ecosystem structure and fishing impacts in the northwestern Mediterranean Sea using a food web model within a comparative approach." Journal of Marine Systems 148: 183-199.

Costanza, R., R. d'Arge, et al. (1997). "The value of the world's ecosystem services and natural capital." Nature 387(6630): 253.

Costello, M. J., M. Coll, et al. (2010). "A census of marine biodiversity knowledge, resources, and future challenges." PloS one 5(8): e12110.

Côté, I. M., E. S. Darling, et al. (2016). "Interactions among ecosystem stressors and their importance in conservation." Proceedings of the Royal Society of London B: Biological Sciences 283(1824).

Crain, C. M., B. S. Halpern, et al. (2009). "Understanding and managing human threats to the coastal marine environment." Annals of the New York Academy of Sciences 1162(1): 3962.

Cheng, B. S., A. H. Altieri, et al. (2019). "Can marine reserves restore lost ecosystem functioning? A global synthesis." Ecology 100(4): e02617.

Christensen, V. and J. Maclean (2011). Ecosystem approaches to fisheries: a global perspective. Cambridge, Cambridge University Press.

Christensen, V., C. Walters, et al. (2008). "Ecopath with Ecosim version 6 user guide." Lenfest Ocean Futures Project, University of British Columbia, Vancouver.

Christensen, V. and C. J. Walters (2004). "Ecopath with Ecosim: methods, capabilities and limitations." Ecological Modelling 172(2): 109-139.

Chuenpagdee, R. and S. Jentoft (2018). Transdisciplinarity for small-scale fisheries governance, Springer.

Di Franco, A., J. G. Plass-Johnson, et al. (2018). "Linking home ranges to protected area size: The case study of the Mediterranean Sea." Biological Conservation 221: 175-181.

Di Franco, A., P. Thiriet, et al. (2016). "Five key attributes can increase marine protected areas performance for small-scale fisheries management." Scientific reports 6: 38135.

Di Lorenzo, M., J. Claudet, et al. (2016). "Spillover from marine protected areas to adjacent fisheries has an ecological and a fishery component." Journal for Nature Conservation 32: 62-66.

Edgar, G. J., R. D. Stuart-Smith, et al. (2014). "Global conservation outcomes depend on marine protected areas with five key features." Nature 506: 216.

Fenberg, P. B., J. E. Caselle, et al. (2012). "The science of European marine reserves: Status, efficacy, and future needs." Marine Policy 36(5): 1012-1021.

Fulton, E. A., N. J. Bax, et al. (2015). "Modelling marine protected areas: insights and hurdles." Philosophical Transactions of the Royal Society B: Biological Sciences 370(1681): 20140278.

Fulton, E. A., F. Boschetti, et al. (2015). "A multi-model approach to engaging stakeholder and modellers in complex environmental problems." Environmental Science \& Policy 48: 4456. 
Gaines, S. D., C. White, et al. (2010). "Designing marine reserve networks for both conservation and fisheries management." Proceedings of the National Academy of Sciences 107(43): 18286-18293.

Gell, F. R. and C. M. Roberts (2003). "Benefits beyond boundaries: the fishery effects of marine reserves." Trends in Ecology \& Evolution 18(9): 448-455.

Giakoumi, S., J. McGowan, et al. (2018). "Revisiting "success" and "failure" of marine protected areas: a conservation scientist perspective." Frontiers in Marine Science 5: 223.

Giakoumi, S. and A. Pey (2017). "Assessing the effects of marine protected areas on biological invasions: a global review." Frontiers in Marine Science 4: 49.

Giakoumi, S., A. Pey, et al. (2019). "Exploring the relationships between marine protected areas and invasive fish in the world's most invaded sea." Ecological applications 29(1): e01809.

Giakoumi, S., C. Scianna, et al. (2017). "Ecological effects of full and partial protection in the crowded Mediterranean Sea: a regional meta-analysis." Scientific reports 7(1): 8940.

Giron-Nava, A., C. C. James, et al. (2017). "Quantitative argument for long-term ecological monitoring." Marine Ecology Progress Series 572: 269-274.

Gómez, S. and J. Lloret (2017). The Small-Scale Fisheries Guidelines as a Tool for Marine Stewardship: The Case of Cap de Creus Marine Protected Area, Spain. The Small-Scale Fisheries Guidelines, Springer: 401-420.

Goñi, R., S. Adlerstein, et al. (2008). "Spillover from six western Mediterranean marine protected areas: evidence from artisanal fisheries." Marine Ecology Progress Series 366: 159-174.

Grorud-Colvert, K., J. Claudet, et al. (2014). "Marine protected area networks: assessing whether the whole is greater than the sum of its parts." PloS one 9(8): e102298.

Grüss, A., D. M. Kaplan, et al. (2011). "Consequences of adult and juvenile movement for marine protected areas." Biological Conservation 144(2): 692-702.

Guidetti, P., M. Milazzo, et al. (2008). "Italian marine reserve effectiveness: does enforcement matter?" Biological Conservation 141(3): 699-709.

Halpern, B. S., M. Frazier, et al. (2015). "Spatial and temporal changes in cumulative human impacts on the world's ocean." Nature communications 6.

Halpern, B. S., S. E. Lester, et al. (2009). "Spillover from marine reserves and the replenishment of fished stocks." Environmental Conservation 36(4): 268-276.

Halpern, B. S., S. E. Lester, et al. (2010). "Placing marine protected areas onto the ecosystembased management seascape." Proceedings of the National Academy of Sciences 107(43): 18312-18317.

Harrison, H. B., D. H. Williamson, et al. (2012). "Larval export from marine reserves and the recruitment benefit for fish and fisheries." Current Biology 22(11): 1023-1028.

Hereu Fina, B., E. Aspillaga Cuevas, et al. (2017). "Seguiment del medi marí al Parc Natural del Cap de Creus i al Parc Natural del Montgrí, les Illes Medes i el Baix Ter. Memòria 2016."

Heymans, J. J., M. Coll, et al. (2016). "Best practice in Ecopath with Ecosim food-web models for ecosystem-based management." Ecological Modelling.

Hilborn, R. and C. J. Walters (1992). "Quantitative fisheries stock assessment: choice, dynamics and uncertainty." Reviews in fish biology and fisheries 2(2): 177-178.

Horta e Costa, B., J. Claudet, et al. (2016). "A regulation-based classification system for Marine Protected Areas (MPAs)." Marine Policy 72: 192-198.

IUCN-WCPA (2008). Establishing Marine Protected Area Networks: Making it Happen, IUCN-World Commission on Protected Areas, National Oceanic and Atmospheric Administration and The Nature Conservancy.

Katsanevakis, S., M. Coll, et al. (2014). "Invading the Mediterranean Sea: biodiversity patterns shaped by human activities." Marine Ecosystem Ecology 1: 32. 
Lassalle, G., P. Bourdaud, et al. (2014). "A toolbox to evaluate data reliability for whole-ecosystem models: Application on the Bay of Biscay continental shelf food-web model." Ecological Modelling 285: 13-21.

Leenhardt, P., N. Low, et al. (2015). The role of marine protected areas in providing ecosystem services. Aquatic functional biodiversity, Elsevier: 211-239.

Lejeusne, C., P. Chevaldonné, et al. (2010). "Climate change effects on a miniature ocean: the highly diverse, highly impacted Mediterranean Sea." Trends in Ecology \& Evolution 25(4): 250-260.

Leslie, H. M. and K. L. McLeod (2007). "Confronting the challenges of implementing marine ecosystem-based management." Frontiers in Ecology and the Environment 5(10): 540-548.

Lester, S. E., B. S. Halpern, et al. (2009). "Biological effects within no-take marine reserves: a global synthesis." Marine Ecology Progress Series 384: 33-46.

Libralato, S., M. Coll, et al. (2010). "Food-web traits of protected and exploited areas of the Adriatic Sea." Biological Conservation 143(9): 2182-2194.

Lindeman, R. L. (1942). "The trophic-dynamic aspect of ecology." Ecology 23(4): 399-417.

Link, J. (2010). Ecosystem-based fisheries management: confronting tradeoffs, Cambridge University Press.

Link, J. S. (2010). "Adding rigor to ecological network models by evaluating a set of pre-balance diagnostics: a plea for PREBAL." Ecological Modelling 221(12): 1580-1591.

Link, J. S., T. Ihde, et al. (2012). "Dealing with uncertainty in ecosystem models: the paradox of use for living marine resource management." Progress in Oceanography 102: 102-114.

Long, R. D., A. Charles, et al. (2015). "Key principles of marine ecosystem-based management." Marine Policy 57: 53-60.

Lloret, J., S. Biton-Porsmoguer, et al. (2019). "Recreational and small-scale fisheries may pose a threat to vulnerable species in coastal and offshore waters of the western Mediterranean." ICES Journal of Marine Science.

Lloret, J., I. G. Cowx, et al. (2018). "Small-scale coastal fisheries in European Seas are not what they were: Ecological, social and economic changes." Marine Policy 98: 176-186.

Lloret, J., N. Zaragoza, et al. (2008). "Spearfishing pressure on fish communities in rocky coastal habitats in a Mediterranean marine protected area." Fisheries Research 94(1): 84-91.

Lloret, J., N. Zaragoza, et al. (2008). "Biological and socioeconomic implications of recreational boat fishing for the management of fishery resources in the marine reserve of Cap de Creus (NW Mediterranean)." Fisheries Research 91(2-3): 252-259.

Mackinson, S., G. Daskalov, et al. (2009). "Which forcing factors fit? Using ecosystem models to investigate the relative influence of fishing and changes in primary productivity on the dynamics of marine ecosystems." Ecological Modelling 220(21): 2972-2987.

Maris, V., P. Huneman, et al. (2017). "Prediction in ecology: promises, obstacles and clarifications." Oikos 0: 1-12.

Martínez, M. L., A. Intralawan, et al. (2007). "The coasts of our world: Ecological, economic and social importance." Ecological Economics 63(2-3): 254-272.

Maynou, F., M. Sbrana, et al. (2011). "Estimating trends of population decline in long-lived marine species in the Mediterranean Sea based on fishers' perceptions." PloS one 6(7): e21818.

McLeod, K. L., J. Lubchenco, et al. (2005). "Scientific consensus statement on marine ecosystembased management." Signed by 221: 1-21.

MEA (2005). (Millennium Ecosystem Assessment) Ecosystems and human well-being: biodiversity synthesis. World Resources Institute, Washington DC.

Micheli, F., B. S. Halpern, et al. (2004). "Trajectories and correlates of community change in no-take marine reserves." Ecological applications 14(6): 1709-1723. 
Micheli, F., B. S. Halpern, et al. (2013). "Cumulative Human Impacts on Mediterranean and Black Sea Marine Ecosystems: Assessing Current Pressures and Opportunities." PloS one 8(12): e79889.

Morissette, L. (2007). Complexity, cost and quality of ecosystem models and their impact on resilience: a comparative analysis, with emphasis on marine mammals and the Gulf of St. Lawrence PhD thesis, University of British Columbia.

Occhipinti-Ambrogi, A. and D. Savini (2003). "Biological invasions as a component of global change in stressed marine ecosystems." Marine pollution bulletin 46(5): 542-551.

Paine, R. T. (1966). "Food web complexity and species diversity." American Naturalist: 65-75.

Paine, R. T. (1969). "A note on trophic complexity and community stability." The American Naturalist 103(929): 91-93.

Pauly, D., V. Christensen, et al. (1998). "Fishing down marine food webs." science 279(5352): 860863.

Pauly, D., A. Ulman, et al. (2014). "'Reported'versus' likely'fisheries catches of four Mediterranean countries." Scientia Marina 78(S1): 11-17.

Pauly, D. and D. Zeller (2016). "Catch reconstructions reveal that global marine fisheries catches are higher than reported and declining." Nature communications 7: ncomms10244.

Piroddi, C., M. Coll, et al. (2017). "Historical changes of the Mediterranean Sea ecosystem: modelling the role and impact of primary productivity and fisheries changes over time." Scientific Reports.

Piroddi, C., M. Coll, et al. (2015). "Modelling the Mediterranean marine ecosystem as a whole: addressing the challenge of complexity." Marine Ecology Progress Series 533: 47-65.

Poloczanska, E. S., M. T. Burrows, et al. (2016). "Responses of marine organisms to climate change across oceans." Frontiers in Marine Science 3: 62.

Prato, G., C. Barrier, et al. (2016). "Assessing interacting impacts of artisanal and recreational fisheries in a small Marine Protected Area (Portofino, NW Mediterranean Sea)." Ecosphere 7(12).

Roberts, C. M., B. C. O'Leary, et al. (2017). "Marine reserves can mitigate and promote adaptation to climate change." Proceedings of the National Academy of Sciences 114(24): 6167-6175.

Rochet, M.-J. and V. M. Trenkel (2003). "Which community indicators can measure the impact of fishing? A review and proposals." Canadian Journal of Fisheries and Aquatic Sciences 60(1): 86-99.

Sala, E., E. Ballesteros, et al. (2012). "The structure of Mediterranean rocky reef ecosystems across environmental and human gradients, and conservation implications." PloS one 7(2): e32742.

Sala, E., S. Giakoumi, et al. (2017). "No-take marine reserves are the most effective protected areas in the ocean." ICES Journal of Marine Science 75(3): 1166-1168.

Scianna, C., F. Niccolini, et al. (2019). "Organization Science improves management effectiveness of Marine Protected Areas." Journal of Environmental Management 240: 285-292.

Scott, E., N. Serpetti, et al. (2016). "A Stepwise Fitting Procedure for automated fitting of Ecopath with Ecosim models." SoftwareX.

Shin, Y.-J. and L. J. Shannon (2010). "Using indicators for evaluating, comparing, and communicating the ecological status of exploited marine ecosystems. 1. The IndiSeas project." ICES Journal of Marine Science: Journal du Conseil 67(4): 686-691.

Steenbeek, J. (2018). "Diet Calculator - Quick Reference Guide. Version 0.8.5, 11 June 2018. https://figshare.com/articles/Diet_calculator_guide_pdf/11369916. Safenet project - EUDGMARE (MARE/2014/41). Barcelona." 
861
Steenbeek, J., X. Corrales, et al. (2018). "Ecosampler: A new approach to assessing parameter uncertainty in Ecopath with Ecosim." SoftwareX 7: 198-204.

Stelzenmüller, V., F. Maynou, et al. (2008). "Spatial assessment of fishing effort around European marine reserves: implications for successful fisheries management." Marine pollution bulletin 56(12): 2018-2026.

Stergiou, K. I. and V. S. Karpouzi (2001). "Feeding habits and trophic levels of Mediterranean fish." Reviews in fish biology and fisheries 11(3): 217-254.

Tam, J. C., J. S. Link, et al. (2017). "Towards ecosystem-based management: identifying operational food-web indicators for marine ecosystems." ICES Journal of Marine Science 74(7): 20402052.

Ulanowicz, R. and C. Puccia (1990). "Mixed trophic impacts in ecosystems." Coenoses 5(1): 7-16.

Valls, A., M. Coll, et al. (2015). "Keystone species: toward an operational concept for marine biodiversity conservation." Ecological Monographs 85(1): 29-47.

Valls, A., D. Gascuel, et al. (2012). "Modeling trophic interactions to assess the effects of a marine protected area: case study in the NW Mediterranean Sea." Marine Ecology Progress Series 456(201-214): 98.

Vilas, D., M. Coll, et al. (Submitted). "The effects of marine protected areas on ecosystem recovery and fisheries using a comparative modelling approach." Aquatic Conservation: Marine and Freshwater Ecosystems.

Walters, C., V. Christensen, et al. (1997). "Structuring dynamic models of exploited ecosystems from trophic mass-balance assessments." Reviews in fish biology and fisheries 7(2): 139172.

Worm, B., E. B. Barbier, et al. (2006). "Impacts of biodiversity loss on ocean ecosystem services." science 314(5800): 787-790. 